\title{
Awareness, Knowledge and Perception of Non-Clinical Staff of an Eye Institute in Amritsar Regarding Eye Donation
}

\author{
Milan Rai ${ }^{*}$, Parkash R02 ${ }^{2}$ Parkash TO $^{3}$ and Mahajan $\mathrm{S}^{3}$ \\ ${ }^{1}$ Research Fellow and Clinical Optometris, Dr Om Parkash Eye Institute, India \\ 2Department of Cataract Surgery, Dr Om Parkash Eye Institute, India \\ ${ }^{3}$ Department of Cataract and Refractive Surgery, Dr Om Parkash Eye Institute, India
}

*Corresponding author: Milan Rai, Dr Om Parkash Eye Institute, India, Email: raimilan054@gmail.com

\section{Research Article \\ Volume 4 Issue 3}

Received Date: September 05, 2019

Published Date: October 04, 2019

DOI: $10.23880 /$ oajo-16000186

\section{Abstract}

Introduction: According to WHO, 'Blindness is defined as visual acuity of less than $3 / 60$, or a corresponding visual field loss to less than $10^{\circ}$, in the better eye with the best possible correction. According to NPCB (3).90\% of the global cases of ocular trauma and corneal ulceration which ultimately leads to corneal blindness occurs in developing nations that indicates the burden of corneal diseases in our country. Corneal blindness constitutes $1 \%$ of the total 12 million blind persons in India. Corneal transplantation has become major treatment option for restoring the sight of corneal blind persons.

Methodology: This is a Questionnaire based study conducted between December 2018 - June 2019 at Dr Om Parkash Eye Institute (Main Hospital), Amritsar, India. Out of 150 all non-clinical staff from Dr Om Parkash Eye Institute (Main Hospital), a total of 150 staff was taken for study.

Results: Out of 150 participants, 96(64\%) were aware of eye donation and 54(36\%) were unaware of eye donation. Out of150 participants, $99(66 \%)$ were interested to donate their eyes after death and 51(34\%) were not interested.

Conclusion: More than one third (36\%) non clinical staff of the above-mentioned institute is unaware of the eye donation. Still more than three fifth of the total participants are unaware that cornea is transplanted in eye donation. Most of them have the misconceptions that whole eyeball is transplanted. Most of the participants almost three fifth participants came to know about the eye donation through media. Still many people are unaware about the eye donation and its importance. Due to their unawareness, family members objected while donating the eye.

\section{Introduction}

According to WHO, 'Blindness is defined as visual acuity of less than $3 / 60$, or a corresponding visual field loss to less than $10^{\circ}$, in the better eye with the best possible correction. Corneal diseases are the major causes of vision loss and blindness in the world as per WHO [1]. Approximately, 6.8 million people have corneal blindness which consists of about 1 million bilaterally blind people [2]. Currently, there are 120000 corneal blind persons 
with addition of 25,000-30,000 cases every year in India. According to NPCB [3] 90\% of the global cases of ocular trauma and corneal ulceration which ultimately leads to corneal blindness occurs in developing nations that indicates the burden of corneal diseases in our country [4] Corneal blindness constitutes $1 \%$ of the total 12 million blind persons in India [5]. Corneal transplantation has become major treatment option for restoring the sight of corneal blind persons [6]. The causes of blindness are Cataract (62.6\%),Uncorrected refractive errors (19.7\%), Corneal Blindness (0.90\%), Glaucoma (5.80\%), Surgical Complication $(1.20 \%)$, Posterior Capsular Opacification (0.90\%), Posterior Segment Disorders (4.70\%) and Others (4.19\%).The blind population will double by 2020 according to WHO [7]. Keratoplasty or Corneal transplantation is only the treatment for several cornealpathologies. The first successful corneal transplantation by done by Zirm in 1906 [8]. Keratoplasty is a surgical procedure where the damaged or diseased cornea is removed and replaced by a healthy cornea after the death of donor that is why it is called as sight storing surgery for corneal blindness [9]. Keratoplasty may be partial thickness or full thickness. Partial thickness is anterior or posterior lamellar keratoplasty and full thickness is penetrating keratoplasty. Various types of keratoplasty include Superficial Lamellar Keratoplasty, Penetrating Keratoplasty, Deep Anterior Lamellar Keratoplasty, Endothelial Keratoplasty, Limbal Stem Cell Grafting etc. Keratoplasty is indicated to improve vision in cases of keratoconus, scarring, corneal dystrophies and corneal degenerations. Tectonic grafting helps to restore and preserve the corneal integrity having severe structural changes such as thinning. Infected corneal tissue unresponsive to antimicrobial therapy can be removed by therapeutic corneal transplantation. One of the rare indications is to improve the cosmetic appearance of the eye by cosmetic grafting [10]. The act of donating one's eyes after death is called eye donation which is a charitable and voluntary deed. It is often called as best means of social service. Corneal blindness can be cured by corneal transplantation. The eyes of a dead person can be used only if they are taken out within 6 hours of death. The eyes should be kept wet by sprinkling water on them or by placing pieces of cotton wool soaked in water till the eye surgeon arrives. The charitable organization called eye bank facilitates the removal of eyes, processing and evaluation and distribution of eyes to needy [11]. Any gender and person of any age can donate eye.An individual with refractive errors can also donate eye. The persons who have been operated for cataract surgery can donate eyes. The individuals suffering from diabetics, hypertension, asthma and those without communicable diseases can also donate eyes. Contraindications of keratoplasty are certain systemic infections such as Human Immunodeficiency Virus (HIV), viral hepatitis, syphilis, tuberculosis, infectious diseases and certain diseases of Central Nervous System such as Creutzfeldt-Jakob Disease, Alzheimer disease and other dementias, Parkinson disease, Multiple sclerosis, etc. Many inflammatory and certain ocular diseases which may compromise the graft outcome such as retinoblastoma and corneal refractive surgery are also contra indicatory factors for keratoplasty [12]. Religious and cultural beliefs (e.g. significance of eyes), Objections from the family members, Health problem affecting the eye, Disfigurement and mutilation etc are the barriers of eye donation [13].

\section{Importance of Our Study}

This study is conducted in order to assess the awareness and perspective of the non-clinical staff of an eye institute. The non-clinical staff is directly or indirectly connected to the patients during various states and while carrying out different procedures ranging from administrative to surgical procedures. Their clear understanding about the eye donation will certainly have great impact on the implementation of eye donation programs. Their active participations in counselling the patients and public regarding eye donation can definitely spread the awareness which can decrease the number of corneal blind persons within a particular area and if initiated throughout the nation, can bring considerable changes in the present day scenario regarding corneal blindness. So, this study is designed in order to assess the level of awareness in non-clinical staff and to aware them regarding eye donation first and through them patients and public people can be aware.

\section{Methodology}

a) Study design: Questionnaire based study.

b) Study duration: December 2018 - June 2019.

c) Study setting: Dr Om Parkash Eye Institute (Main Hospital), Amritsar, India.

d) Study Participants: Out of all non-clinical staff from $\mathrm{Dr}$ Om Parkash Eye Institute (Main Hospital), a total of 150 staff was taken for study.

e) Sample size: 150 .

f) Sampling technique: Convenient sampling. 


\section{Inclusion Criteria}

a) All the Non clinical staff including administrative staff, Management staff and Opticians.

\section{Exclusion Criteria}

a) All Clinical Staff (Ophthalmologists, Optometrists, Nurses and Pharmacists).

b) Unwilling participants.

This study was conducted after receiving the ethical approval from the ethical committee of Dr Om Parkash Eye Institute. The self-guided questionnaire was prepared according to the latest literature. The list of questionnaire (objective type) was prepared and got validated by chief of Cornea department, chief of General Ophthalmology and head of the department of Optometry. This was questionnaire based study conducted among the nonclinical staff of Dr Om Parkash Eye Institute, Amritsar. SPSS was used to measure the internal consistency. All the participants were given the questionnaire consisting of two parts. First part consists of demographic data and second part consists of questionnaire based on the eye donation and its various aspects. The second part was entirely eye donation based. The questions related to their awareness of eye donation, their knowledge regarding the procedure of eye transplantation, source of information regarding eye donation, their willingness and belief to donate eyes were included. The questions were all objective type. Once their responses were received, all results obtained from the non-clinical staff were analyzed.

\section{Results}

Out of 150 participants, 84(56\%) were males and $66(44 \%)$ were females. The mean age of the participants was 34.23years.Out of 150 participants, 78(52\%) of the participants were between $20-30$ years, 55(36.66\%) were between $30-40$ years and 17 participants $(11.34 \%)$ were above 40 years of age. Out of 150 participants, 96(64\%) were aware of eye donation and 54(36\%) were unaware of eye donation. Out of 96 participants who were aware of eye donation, $36(37.56 \%)$ participants responded that cornea is transplanted while doing eye donation. $2(2.08 \%)$ participants responded that retina is transplanted while donating eye. 55(57.3\%) participants responded that whole eyeball is transplanted while donating eye and $3(3.125 \%)$ participants responded that iris is transplanted. Out of 96 participants who were aware of eye donation, $73(76.04 \%)$ responded media as source of information. 11(11.45\%) responded hospital campaign as the source of information. 9(9.375\%) responded eye-care professionals as the source of information and $3(3.125 \%)$ responded other sources of information. Out of150 participants, 99(66\%) were interested to donate their eyes after death and 51(34\%) were not interested. Out of 99 interested to donate eyes 95(95.95\%) participants responded pleasure to help the bind as the reason for donating their eyes whereas $4(4.04 \%)$ participants responded other reasons. Out of 51 participants not willing to donate eyes, none of them responded religious belief and fear for facial disfigurement as the reasons for not willing to donate eyes. 27(52.94\%) and 24(47.05\%) responded disagreement from family and any other reasons respectively as the reasons for not willing to donate eyes. Out of 96 participants who were aware of eye donation, $26(27.08 \%)$ participants responded that the eye can be removed from living person. 54(56.25\%) participants responded eye cannot be removed from living person. $6(6.25 \%)$ participants responded that eye can be removed from living person with the consent of doctor and $10(10.41 \%)$ participants responded that they did not. Among 96 participants who were aware of eye donation, 90(93.75\%) participants responded that eyes should be removed from donor by ophthalmologist. 3(3.125\%) participants responded that eyes should be removed from donor by optometrists. $2(2.08 \%)$ participants responded that eyes should be removed from donor by ophthalmic technicians and $1(1.04 \%)$ responded that eye can be removed from donor by anyone who is expert in removing the eyes. Out of 96 participants who were aware of eye donation, $10(10.41 \%)$ responded that eyes can be removed any time after death for donation. $33(34.37 \%)$ responded that eyes can be removed after 6 hours of death. $42(43.75 \%)$ responded that eyes can be removed within 24 hours of death for donation and $11(11.45 \%)$ responded that they didn't know. Out of 96 participants, 63(65.625\%) participants responded (YES) that a person suffering from communicable disease at the time of death can donate eyes whereas 33(34.375\%) responded (NO) that a person suffering from communicable diseases cannot donate eyes after death. Out of 96 participants, 71(73.95\%) participants responded (No) that a person having corneal pathologies cannot donate eyes. 25(26.04\%) participants responded (yes) that a person having corneal pathologies can donate eyes. Out of 96 participants who were aware of eye donation, $30(31.25 \%)$ responded(YES) that eye donation can restore vision in all types of blindness whereas $66(68.75 \%)$ participants responded(NO) that eye donation cannot restore vision in all types of blindness. 


\section{Discussion}

In a study conducted by Bhavna, et al. Awareness index was statistically more in age group $>40$. Partially/Fully aware participants took less than 12 hours for motivation, which was statistically significant (Chi square $=106 . p<0.001)$. The ratio of aware subjects to unaware subjects was $2: 1$. Grief counsellors (57.5\%) had the most influence among the causes that were facilitators of donation (19). In the study conducted by Raj Kumar et al, among adults in rural Pondicherry, India, out of 196 participants, about $81 \%$ were aware of eye donation. There was a significant relationship between education and occupation with awareness. Television (65.2\%) was the main source of information. The employed persons were significantly more aware about the correct timing for eye donation. The predictors for awareness about eye donation were education and occupation. In our study, the level of awareness of non-clinical staff were assessed on the basis of the responses as received according to questionnaire and those who were not willing to donate the eyes were motivated for eye donation. All the parameters were assessed very attentively and analyzed comparatively keeping every criterion in mind. The possible reasons for willing to donate eyes as well as reasons for unwilling to donate the eyes were analyzed. All the aspects including the socio-economic as well as religious beliefs etc. were put into strong considerations in our study. The general protocols followed while transplanting the cornea after the death of an individual were described in brief to all the participants of the study after explaining the brief pre requisites for the corneal transplantation. The main objective of explaining the pre requisites and the protocols involved in eye donation was to make them effectively capable to aware the patients visiting our institute for treatment. According to our study, 54(36\%) were unaware of eye donation. Only $96(64 \%)$ were aware of eye donation. Only 36(37.56\%) participants out of 96 participants who were aware of eye donation responded that cornea is transplanted from the donor after death. Media was reported as the source of information by 73(76.04\%) participants out 96 aware participants. Out of 150 participants, only $99(66 \%)$ were willing to donate eyes. 27(52.94\%) participants out of 51 unwilling participants responded that family objected to donate eyes after death. Out of 96 participants who were aware of eye donation,54(56.25\%) responded that eye cannot be transplanted from living person.32 participants responded that eye can be donated from living person either with or without the consent of doctor.10 participants responded that they didn't know about this $90(93.37 \%)$ participants, out of 96 participants who were aware of eye donation, responded that the eye should be removed from the donor by the ophthalmologist whereas $3(3.125 \%)$ participants out of 96 responded that the eye should be removed from the donor by an optometrist. Only 33(34.37\%) out of 96 , responded that the cornea from the donor should be removed within 6 hours of death of donor. 63(65.625\%) out of 96 participants reported that a person suffering from communicable disease can donate the eyes whereas 33 responded he/she cannot. 71(73.95\%) responded that a person with corneal pathology cannot donate eyes whereas 25 participants responded they can. Out of 96 participants who were aware of eye donation, $30(31.25 \%)$ responded that eye donation can cure all types of blindness whereas $66(68.75 \%)$ responded that eye donation cannot cure all types of blindness.

\section{Conclusion}

More than one third (36\%) non clinical staff of the above-mentioned institute is unaware of the eye donation. Still more than three fifth of the total participants are unaware that cornea is transplanted in eye donation. Most of them have the misconceptions that whole eyeball is transplanted. Most of the participants almost three fifth participants came to know about the eye donation through media. Still many people are unaware about the eye donation and its importance. Due to their unawareness, family members objected while donating the eye. It is necessary to raise the level of knowledge among the non-clinical staff. It is necessary to conduct eye awareness program initially targeted for the non-clinical hospital staff and encourage them to pledge their relatives for eye donation. When they are aware about the basic concept of eye donation, they can motivate the patients and public for eye donation. Because of their unawareness many corneas will go waste. So, it is very essential to conduct the awareness programs.

\section{References}

1. Whitcher JP, Srinivasan M, Upadhyay MP (2001) Corneal blindness: a global perspective. Bull World Health Organ 79(3): 214-221.

2. Sinha R, Sharma N, Vajpayee RB (2005) Corneal Blindness-Present Status A look at the leading causes of and current treatment success with blindness worldwide. Cataract \& Refract Surg today. 


\section{Open Access Journal of Ophthalmology}

3. Gupta N, Tandon R, Gupta SK, Sreenivas V, Vashist P (2013) Burden of corneal blindness in India. Indian J Community Med 38(4): 198-206.

4. (2010) National programme for control of blindness. Chandhigarh: DGHS, Government of Punjab.

5. Dadona R, Dadona L, Naduvilath TJ, Mccarty CA, Rao GN (1999) Awareness of eye donation in an urban population in India. Aus NZJ ophthalmol 27(3-4): 166-169.

6. Verma $\mathrm{R}$, Khanna $\mathrm{P}$, Prinja S, Rajput M, Arora V (2011) The national programme for control of blindness in India. Australas Med J 4(1): 1-3.

7. Konstantinos D, Georgios B, Dimitrios M (2018) Trends in Indications and Techniques of Corneal Transplantation from 1999 through 2015 at a Tertiary Referral Center in Athens, Greece. J Ophthalmol 2018: 1-7.

8. Magdum R, Arun S, Mushtaq I, Sharma N (2015) To study awareness and willingness of eye donation among paramedical workers. J Clin Ophthalmol Res 3(2): 95-97.

9. Forrester J, Kuffova L (2004) Corneal Transplantation. London: Imperial College Press, pp: 8-23.
10. Hjortdal J (2016) Corneal transplantation/ Jesper Hjortdal. pp: 8-27.

11. Ronaki VR, Sheeladevi S, Ramachandran BP, Jalbert I (2014) Awareness regarding eye donation among stakeholders in Srikakulam district in South India. BMC Ophthalmol 14: 25.

12. Lal B, Usgaonkar U, Narvekar H, Venugopal D (2018) Awareness and knowledge on eye donation among Allied Health Sciences, medical, and nursing students in Goa. J Curr Ophthalmol 30(3): 255-262.

13. Singh MM, Rahi M, Pagare D, Ingle GK (2007) Medical students' perception on eye donation in Delhi. Indian J Ophthalmol 55(1): 49-52.

14. Gupta A, Jain S, Jain T, Gupta K (2009) Awareness and perception regarding eye donation in students of a nursing college in bangalore. Indian J Community Med 34(2): 122-125.

15. Williams AM, Muir KW (2018) Awareness and attitudes toward corneal donation: challenges and opportunities. Clin Ophthalmol 12: 1049-1059. 